\title{
Quality Measurement Theory and Application in Bali Tour Group
}

\author{
Yanhong Liu, ${ }^{1,2, a}$, Caijuan $\mathrm{Li}^{1, \mathrm{~b}}$ and Jun Yuan ${ }^{1, \mathrm{C}^{*}}$ \\ ${ }^{1}$ Tourism and Culture Department, Normal College, Shenzhen University, China \\ ${ }^{2}$ Strategy and HR Management Department,Business School, Sichuan University, China \\ a841226273@qq.com, blicaijuanserena@126.com,150006437@qq.com \\ ${ }^{*}$ Corresponding author
}

\begin{abstract}
Keywords: SERVQUAL, Quality gap model, Bali tour, Group product
\end{abstract}
\begin{abstract}
This paper selects Quality Measure Theory as research method which is based on five dimensions of Parasuraman's SERVQUAL to analyze the reliability, responsiveness, assurance, empathy, and tangibility of Bali tourism product. In-depth interview method is also used to testify satisfaction of tour group traveling in Bali through concerned operators, tour leaders, local guides and tourists. The quality gap model analyzes the problems existing in the quality of tourism products and management personnel, service specification, service delivery, marketing communication aspects so as to narrow down the gap between customer expectations and the actual feeling of the service, trying to come up with the practical operations of the breakthrough point in the management of travel products quality, to seek for healthy, profitable and sustainable development of Bali tour market.
\end{abstract}

\section{Introduction}

In an era dominated by buyer's market, good product and service quality is the premise foundation of enterprises and industry development. Tourism products imitation cost is extremely low for their general and unique attributes, which leads to product homogenization and hitchhiking mentality, lack of motivation for innovation. Innovative, humanized and personalized tour group products need to be developed in accordance with the tourism demand of consumers and the current tourism trend.Unique cultural identity and peaceful atmosphere make Bali the most unique of Indonesia's more than 17,000 islands. Bali has tourism as its pillar industry. More than five million tourists visit Bali each year, and $80 \%$ of its residents are in the tourism industry. This paper takes tour group products of Bali island as the research object, and uses the quality measurement to analyze the product composition, so as to further analyze the quality related factors of the products, as well as the relationship between various factors and the whole, to make practical breakthrough for travel agency product quality management.

\section{Research context}

Parasuraman, Zeithaml and Berry (collectively known as the PZB combination) present a five-dimensional view of service quality,reliability, responsiveness, assurance, empathy and tangibility ${ }^{[1]}$. Their "difference theory" is to find out the reasons for the service quality problems and improve the service quality. On the basis of the assertion that service quality is the gap between the service perceived by the customer and the service expected by the customer, they proposed the detection model of five gaps. The gap between the manager's understanding of customer expectations and the actual expectations of customers. Service delivery gap refers to the gap between the quality level of service in the delivery process and the service specification established by the service organization.Gap in market information communication refers to the gap between the information about service quality in market communication and the service quality actually provided by the organization.Customer perceived service quality gap is the gap between customer's actual perceived service quality and their own expected service ${ }^{[2]}$. 
The SERVQUAL model evaluation method is based on the customer perception, that is, the customer's subjective consciousness is the focus of measurement. It measures the customer's expectation of service, and then measures the customer's perception of service, thus calculating the difference between the two and using it as the basis to judge the level of service quality ${ }^{[2]}$.

\section{Methods}

\subsection{In-depth interview}

In-depth interview method is adopted through exchanges with 13 people including operators of Bali group tour organizer and supplier travel agencies, tourists visiting Bali island, Chinese tour leaders and local tour guides in Bali, so as to understand their views on the quality of tourism products and services with unstructured questionnaire being adopted to design open questions.

This paper selects several routes that travel agencies operating in Bali for the market and analyzes their advantages and disadvantages. Bali local travel agencies have to accept orders without the tour fee many times in order to compete for the group, and even pay for the tour in the off-season.The domestic tour group organizers complain that the price competition with the domestic routes is too fierce and it is difficult to attract tourist group without lowering the price. The tour leader thinks that the domestic group can not keep the price so low, and should not make the market worse and worse. The local guides in Bali regard that the local travel agencies could not accept the "gambling group", and then put all the pressure on the guide alone.Tourists as non-travel professionals believe that their efforts should be rewarded with even higher prices which are often quoted from domestic travel agencies. Therefore, a large part of the reason for the low degree of tourists' satisfaction is that the excessive marketing of travel agencies leads to high expectations of tourists.

\subsection{SERVQUAL questionnaire survey}

In this study, we conducted a questionnaire survey among the tourists participating in a group trip to Bali.The questionnaire design of the survey is based on the SERVQUAL measurement model and refers to the travel agency service quality questionnaire designed by Biyan Wen $(2011)^{[3]}$. The service quality of tourism products is measured from five aspects of tangibility,reliability, sensitivity, credibility, and empathy. The service quality of tourism products is evaluated through their respective indicators. The main body of the questionnaire is divided into two parts, with a total of 44 items. Questions 1-22 are the tourists' expectations of the product, while questions 23-44 are the tourists' actual perception of the product quality.

The survey was conducted through tourists who have come back from Bali island as the objects of the survey via Shenzhen or Hongkong airport. They have participated in the tourist group of Bali island within 4 months. A total of 150 questionnaires were issued and 150 were collected, and 138 valid questionnaires were finally obtained, with an effective response rate of $92 \%$.

\section{Findings}

According to interviews through concerned operators, tour leaders, local guides and tourists, most tourists are extremely sensitive to the price, although some tourists in China are willing to pay higher fees for better services. In recent years, price wars have been the main marketing effort for travel agencies, while front-line staffs such as tour guides have been able to increase their income only through more professional and flexible tour escorting skills.

The evaluation of Baili tourists' questionnaire survey shows that all the service quality gaps are negative as Table 1, indicating that tourists are not satisfied with the quality of Bali island's tour group products and believe that the actual performance of Bali island's products and service quality is not as good as their expectations. Among them, the reliability evaluation is the lowest, the gap between expectation and actual perception is the largest, the evaluation of tangibility and empathy is the highest, and the gap between expectation and actual perception is the smallest.In terms of the 
service quality of tourism products and tour guides, the actual evaluation of five service quality attributes, including tangibility, reliability, sensitivity, credibility and empathy, is lower than expectations. According to the service quality gap model, there are four reasons that lead to the service quality gap: management, service specification, service delivery and marketing communication.

Table 1. The evaluation of Baili tourists' questionnaire survey

\begin{tabular}{|c|c|c|c|}
\hline Aattribute & Expectation & Actual Perception & Quality Gap \\
\hline Tangibility & 16.1 & 14.01 & -2.09 \\
\hline Reliability & 21.5 & 16.45 & -5.05 \\
\hline Sensitivity & 17 & 13.46 & -3.54 \\
\hline Credibility & 21.92 & 17.79 & -4.13 \\
\hline Empathy & 15.51 & 12.74 & -2.77 \\
\hline General Average & 4.18 & 3.39 & -0.80 \\
\hline
\end{tabular}

\subsection{Management}

The awareness of service quality is backward. Many managers of travel agencies only want to get the maximum benefit in the shortest time, thus ignoring the pursuit of higher service quality. Ignore the real tourist needs and always follow others. New Bali's tourism products will be quickly copied by other travel agency competitors.

There are blind spots in tourist information management.Travel agency executives are not on the front line of service and usually have less direct exchange with tourists while staffs contact with the customer and understand the customer's expectations and needs. The more middle management level, the more distortion in the process of information uploading and transmission between front-line staff and top management, the lower efficiency of exchange which limit understanding between senior managers and customers on service expectations.

Failure to provide complaint remediation service. Many complainers said they would not have complained if the travel agency had taken a better attitude and been able to admit their mistakes and apologize sincerely. But concerned travel agencies handled with passive way leading to intensified contradiction and inevitable negative effects.

\subsection{Service specifications}

Lack of standardized operation process. The requirements for designers and receptionists are very high in each link of "food, lodging, travel, shopping and entertainment" of tourism products. However, travel agencies are required to make more specific improvements to the market demand, forming an accurate and standard code of conduct. If tourism products are supported only by hardware facilities but lack of soft cultural competitiveness, the concept of service quality cannot be infiltrated at all.

Service design deviates from the intention of managers. The lack of specific quality control objectives, resulting in many unreasonable behaviors as arbitrarily increasing or decreasing itinerary, releasing false advertisements and low quotation, etc. The short-sighted intention will cause damage to all aspects of service quality.

\subsection{Service delivery}

The service staffs are lack of service awareness. The attitude of receptionist, salesperson, operator and tour guide in travel agency is not positive, the service is not active and the problem occurs buck-passing. These phenomena are particularly obvious in small and medium-sized travel agencies, which not only seriously destroy the image of travel agencies, but also affect the empathy, credibility and sensitivity of travel agencies' services.

Supplier does not fulfill the quality commitment.Tourism products involve various links while most of the services are provided by local travel agency suppliers. Sometimes, the dissatisfaction of tourists is not caused by the travel agency organizers themselves, but the suppliers. 
The service levels are not good.Tourists are satisfied with the travel in case that tour guides play significant role. A good tour guide can make an imperfect itinerary perfect and let guests feel at home. Poor tour guides can sometimes make the perfect schedule worse, and when visitors return, they surely make complaints. Excellent tour guides can enhance the tourists' pleasant feelings and increase their satisfaction with the itinerary. However, due to the lack of fair and reasonable salary system and incentive measures, the tour guide's income is not stable which make them not active, and the sensitivity, empathy, reliability and credibility of the service quality are also difficult to be guaranteed.

\subsection{Marketing communication}

Different versions of the same question. The service of travel agencies is often delivered to tourists through external communication channels such as advertising and promotion, while the service delivery is implemented by internal front-line departments. If there is no effective communication between the two sides, the difference between the service commitment and the actual experience of tourists, the service quality perceived by tourists will be reduced.

Unclear information leads to customer misunderstanding. Whether intentionally or not, many travel agencies engage in misleading marketing with unclear information and vague concepts such as "all-inclusive price" and "luxury tour", leading to excessive expectations of tourists. Thus the disappointment of tourists can be imagined, and the trust to travel agencies can be greatly reduced, which affects the loyalty of tourists to travel agencies and their repurchase.

Advertising is quite different from actual service.Advertising is not only the promotion of travel agency products and services, but also the commitment to tourists, especially the promise of service quality.As competition in the tourism service market intensifies, some travel agencies make excessive promises to tourists and even issue false advertisements in order to compete for tourists.

The price of the product is misleading.In order to gain customers in fierce "price war", travel agencies are willing to offer low or even zero price to attract customers. Such practices not only cheat visitors and damage legitimate rights and interests of tourists, but also ultimately affect the integrity of travel agencies and reduce their market image and competitiveness.

\section{Discussion and conclusion}

This paper applies in-depth interview to analyze the problems existing in the current situation of Bali tourism products sold by domestic travel agencies because of the quality gap between the services actually experienced by tourists and the services they expect. The design and sales of tourism products in Bali island are closely connected with all departments of travel agency. As a product of service industry, there are five service quality gaps in the products. The gaps come from the understanding of managers, service quality standards, service delivery, market information dissemination and customer perception service quality.

This paper also uses the quality measurement theory to collect the gap between actual service and expected service of tourists participating in Bali island tourism routes. Based on SERVQUAL service quality gap model, countermeasures and suggestions for Bali tourism products are obtained. In terms of management personnel, it is necessary to pay attention to market research to understand consumer demand, improve the smooth communication within the organization and establish effective remedial service mechanism. In terms of service specification, it is necessary to establish specific service quality control objectives, service contents and service procedures standardization. In terms of service delivery, it is necessary to pay attention to human resource development and management, select appropriate suppliers and implement effective control. In terms of marketing communication, it is necessary to build the integration of external exchange, effectively manage the expectations of tourists, make every effort to be realistic in advertising, and set appropriate prices according to product quality. 


\section{Acknowledgement}

This research was financially supported by Finance Department Foundation of Guangdong (Grant NO.Z201827), Guangdong Higher Education Teaching Reform Project Foundation(Grant NO.201627334),Philosophy and Social Sciences of Guangdong Province "13th Five-Year" Project Planning(Grant NO.GD16CGL14) and Tourism Creative Planning Competition Funds for University students(Grant NO.2018261007) .

\section{References}

[1] A.Parasuraman,V.A. Zeithaml, L.L.Berry, A conceptual model of service quality and its implications for future research[J]. Journal of Marketing, vol.49(3), pp.41-50,1985.

[2] A.Parasuraman,V.A. Zeithaml, L.L.Berry, SERVQUAL: a multiple item scale for measuring consumer perceptions of service quality[J]. Journal of Retailing, vol.64(1), pp.12-40,1988.

[3] B.Y.Wen, The quality theory and empirical effect of customer perception service of tourist enterprises[M].Beijing:Science Press, pp. 44-48, 2011.

[4] C.A.Gunn, V.Turgut, Tourism planning: basics concepts cases[M].New York:Routledge, pp.134-141,2002.

[5] L.J.Su,S.R.Swanson,X.H.Chen,The effects of perceived service quality on repurchase intentions and subjective well-being of Chinese tourists: The mediating role of relationship quality[J].Tourism Management, vol.52, pp.82-95,2016. 